\title{
CaMKII Regulation of Cardiac Ion Channels
}

\author{
Donald M. Bers, Ph.D. and Eleonora Grandi, Ph.D. \\ Department of Pharmacology, University of California, Davis
}

\begin{abstract}
Calcium/calmodulin-dependent kinase II (CaMKII) is a multifunctional serine/threonine kinase expressed abundantly in the heart. CaMKII targets numerous proteins involved in excitation contraction coupling and excitability and its activation may simultaneously contribute to heart failure and cardiac arrhythmias. In this review, we summarize the modulatory effects of CaMKII on cardiac ion channels function and expression and illustrate potential implications in the onset of arrhythmias via a computer model.
\end{abstract}

\section{Keywords}

CaM kinase; ion channels; arrhythmia; heart failure; computer modeling

\section{Introduction}

Excitation contraction coupling (ECC) is a mechanism by which membrane depolarization controls the amount of $\mathrm{Ca}$ entering the myoplasm and activating contraction, but it also includes feedbacks, whereby Ca regulates the gating of ion channels that are responsible for cardiac excitation. The $\mathrm{Ca}$ binding protein calmodulin $(\mathrm{CaM})$ is a major mediator of this $\mathrm{Ca}$-dependent modulation of ion channels through direct $\mathrm{Ca}-\mathrm{CaM}$ binding or activation of $\mathrm{Ca} / \mathrm{CaM}$ dependent kinases (e.g. CaMKII) and phosphatases (e.g. calcineurin). CaMKII is a multifunctional protein kinase expressed abundantly in the heart. CaMKII is known to phoshorylate numerous target proteins involved in $\mathrm{Ca}$ mobilization (Fig. 1), e.g. Ca influx, release from and uptake into the sarcoplasmic reticulum (SR). More recent findings are that CaMKII modulates sarcolemmal $\mathrm{Na}$ and $\mathrm{K}$ channels. This can influence myocyte $\mathrm{Ca}$ regulation and also confers further $\mathrm{Ca}$ dependence to electrophysiological effects (and makes a complex feedback system).

CaMKII has also emerged recently as potentially a major mechanism of pathological signaling in heart failure (HF), where its expression and activity are greatly enhanced, and where CaMKII overexpression causes HF (1-3). Upregulation of CaMKII activity and expression seems to be a general feature of cardiomyopathy from diverse causes in patients and animal models, suggesting the hypothesis that CaMKII is a signaling molecule in cardiomyopathy. In this setting CaMKII may also be arrhythmogenic, due to altered cardiac repolarization and $\mathrm{Ca}$ handling. Indeed, CaMKII may be a key pharmacological target that acts upstream of ion channels and Ca regulatory pathways. Moreover, CaMKII inhibition may be a viable therapeutic target in the treatment of common forms of cardiac disease.

Mathematical models of cardiomyocytes provide a useful framework to advance our understanding of molecular mechanisms underlying cardiac arrhythmias and to consider

Correspondence: Donald M Bers, Ph.D., Department of Pharmacology, University of California, Davis, 451 Health Sciences Drive, GBSF Room 3513, Davis, CA 95616-8636, Phone: (530) 752-6517, Fax: (530) 752-7710, Email: dmbers@ucdavis.edu. 
therapeutic targets. Recent models have incorporated elements of the CaMKII signaling cascade to study the role of CaMKII in regulating cardiomyocyte contractility and excitability (4-8). In this review, we will discuss the functional consequences of CaMKII activity on cardiac ion channels (Fig. 1) and will illustrate using a mathematical model how these effects may underlie arrhythmogenic mechanisms for both triggered activity and reentry.

\section{Ca Channels}

The L-type Ca channel opens upon cell depolarization, serving as the primary entry point for $\mathrm{Ca}$ into cardiomyocytes. Gating of this channel is directly mediated by $\mathrm{Ca} / \mathrm{CaM}$ through $\mathrm{Ca}$ dependent inactivation $(\mathrm{CDI})$. Ca which either enters the myocyte via Ca current $\left(\mathrm{I}_{\mathrm{Ca}}\right)$ or is released from the sarcoplasmic reticulum (SR) binds to $\mathrm{CaM}$ tethered to the channel Cterminus, altering the interaction of $\mathrm{CaM}$ with the $\mathrm{Ca}$ channel $\mathrm{C}$-terminus, thereby accelerating inactivation (9). CDI is an important negative feedback mechanism. When the myocyte has relatively high $\mathrm{Ca}$ load and large $\mathrm{Ca}$ transients, enhanced $\mathrm{I}_{\mathrm{Ca}}$ inactivation limits further $\mathrm{Ca}$ influx. Conversely, when myocyte $\mathrm{Ca}$ is low and SR Ca release is small, there is less CDI and enhanced $\mathrm{Ca}$ entry which increases SR Ca content. The presence of CDI also alters action potential duration (APD) which also controls Ca levels in the myocyte. With large Ca releases there is strong CDI, which limits integrated $\mathrm{I}_{\mathrm{Ca}}$ influx thereby shortening the APD and further limiting $\mathrm{Ca}$ entry, and the earlier repolarization would also favor additional $\mathrm{Ca}$ extrusion via $\mathrm{Na} / \mathrm{Ca}$ exchange (10).

$\mathrm{Ca} / \mathrm{CaM}$ also indirectly regulates the $\mathrm{Ca}$ channel to enhance L-type $\mathrm{I}_{\mathrm{Ca}}\left(\mathrm{I}_{\mathrm{CaL}}\right)$ via activation of CaMKII. This process is functionally seen as a positive staircase of $\mathrm{I}_{\mathrm{CaL}}$, in which amplitude increases and inactivation slows over a series of several pulses after a resting interval (11).

CaMKII-mediated enhancement of $\mathrm{I}_{\mathrm{CaL}}$ may contribute to the increased contraction strength obtained with faster heart rates which improves cardiac performance during exercise (12). In fact, since CaMKII is sensitive to the frequency of Ca transients, CaMKII is ideally suited to respond to changes in cardiac rhythm. Thus, the positive regulation of the channel by CaMKII may partly offset reduced L-type Ca channel availability at high heart rates caused by direct $\mathrm{Ca} / \mathrm{CaM}$-dependent inactivation. This gating phenomenon requires $\mathrm{Ca}$ influx (it is not seen when $\mathrm{Ba}$ is the charge carrier and is more strongly apparent when local $\mathrm{Ca}$ influx is amplified by SR Ca release), and it is therefore termed Ca-dependent facilitation (CDF). CDF of $\mathrm{I}_{\mathrm{CaL}}$ coexist with CDI, where CDI responds rapidly (during the same beat), while CDF occurs more slowly (from beat to beat). Some studies even claimed that progressive decrease in SR Ca release (negative staircase in rat) and CDI is responsible for observed CDF $(13,14)$. However, CDF is quite similar in species which exhibit positive staircases, and even when SR Ca release is blocked (11).

Several groups have demonstrated that CDF is mediated by CaMKII dependent phosphorylation. Early studies showed that pharmacological inhibition of CaMKII abolishes CDF in the heart (15-17). Moreover, addition of activated CaMKII to the cytoplasmic side of the sarcolemma results in phosphorylation of the LTCC complex, inducing high activity (mode 2) gating that is characterized by long, frequent openings and is consistent with CDF (18).

As for the targets of CaMKII phosphorylation, Hudmon et al. showed that CaMKII phosphorylates the $\alpha_{1 \mathrm{C}}$ subunit and that tethering of CaMKII to the $\alpha_{1 \mathrm{C}}$ carboxy-terminus is an essential molecular feature of $\mathrm{CDF}$, because mutations to a putative $\mathrm{C}$-terminus binding site prevent CDF. More recently, Grueter et al. (19) showed that CaMKII binds to the $\beta_{2 \mathrm{a}}$ subunit of the L-type Ca channel and preferentially phosphorylates Thr498 in $\beta_{2 \mathrm{a}}$. In addition, mutation of Thr498 to Ala (T498A) in $\beta_{2 a}$ results in ablation of CaMKII-mediated $\mathrm{I}_{\mathrm{CaL}}$ facilitation in cardiomyocytes. 
By overexpressing CaMKII $\delta_{C}$ in transgenic mouse myocytes as well as acutely in rabbit myocytes $\mathrm{I}_{\mathrm{CaL}}$ amplitude was increased and inactivation was slowed $(20,21)$, consistently with tonic CDF. I $\mathrm{CaL}$ amplitude could be reduced back to control levels by blocking CaMKII with KN-93 (20) or AIP (21).

It is now well accepted that CaMKII modulates $\mathrm{I}_{\mathrm{CaL}}$, and that this modulation may be important under pathophysiological conditions (e.g. arrhythmias). Interestingly, a transgenic mouse model of cardiac hypertrophy that overexpresses CaMKIV and also shows increased CaMKII activity, showed an increased propensity for ventricular arrhythmias (22). This was caused by triggered activity due to early afterdepolarizations resulting from an inward current during the late plateau phase of the action potential. The increased propensity for arrhythmias has been attributed to enhanced open probability of L-type Ca channels due to increased activity of CaMKII (22). Additionally, in the presence of the CaMKII-inhibitor KN-93, both the increased Ca channel open probability as well as the increased occurrence of arrhythmias were reversed to control values (22). Enhanced CaMKII activation seems to play a major role in $\mathrm{I}_{\mathrm{CaL}}$ remodeling in a murine model of pressure overload HF (3). Indeed, in cardiomyocytes from these animals $\mathrm{I}_{\mathrm{CaL}}$ amplitude was increased and the decay slowed, suggesting a role for CaMKII. In HF myocytes CDF could not be induced, suggesting that $\mathrm{I}_{\mathrm{CaL}}$ was already maximally activated. In addition, the HF-related alterations were recapitulated by application of exogenous CaMKII on control myocytes, whereas exogenous CaMKII did not produce any effect on failing myocytes. These findings implicate increases in CaMKII activity as a direct mechanism governing HF-related changes in $\mathrm{I}_{\mathrm{CaL}}$ and foster the emerging importance of CaMKII as an anti-arrhythmic target.

T-type $\mathrm{Ca}\left(\mathrm{I}_{\mathrm{CaT}}\right)$ current is present to a variable extent in pacemaking, atrial and conduction cells. In the ventricle T-type channels are expressed during cardiac development until the end of the fetal/neonatal period (23), then their expression decreases and there is little or no $\mathrm{I}_{\mathrm{Ca}, \mathrm{T}}$ in normal adult ventricular myocytes. Significant $\mathrm{I}_{\mathrm{CaT}}$ may reappear in ventricular myocytes during the development of cardiac hypertrophy and failure (24-26). T-type Ca channels are phosphorylated by CaMKII, which increases the probability of single channel openings (27, 28 ) and is also upregulated in hypertrophied ventricles (29). Thus, the enhanced CaMKII activity in hypertrophic and failing hearts could further enhance T-type Ca channel openings. However, the potential role of CaMKII signaling to regulate cardiac $\mathrm{I}_{\mathrm{CaT}}$ has not yet been fully explored. At this point one might only speculate that the enhanced $\mathrm{I}_{\mathrm{Ca}, \mathrm{T}}$ activation in myocytes may enhance their automaticity, and thus contribute to arrhythmogenesis.

\section{Na Channels}

The sodium current $\left(\mathrm{I}_{\mathrm{Na}}\right)$ is responsible for the rapid depolarization of the membrane potential, which initiates the electrical cascade responsible for cardiac rhythm. Numerous life-threatening arrhythmias arise from $\mathrm{Na}$ channel dysfunction, thus illustrating its central role in controlling cardiac excitability. Gating of the Na channel appears to be modulated by $\mathrm{Ca}$. However, the mechanism of this modulation (direct $\mathrm{Ca}$ binding and/or indirect regulation via $\mathrm{CaM}$ or CaMKII) is not yet fully resolved.

Wingo et al. (30) proposed a novel mechanism for modulation of Na channel function where $\mathrm{Ca}$ ions bind directly to $\mathrm{hH} 1$ via an EF-hand motif in the C-terminal domain. However, more recent and direct experiments have provided evidence against the possibility that $\mathrm{Ca}$ binds to this region (31).

Tan et al. (32) have shown that CaM enhances $\mathrm{I}_{\mathrm{Na}}$ slow inactivation by binding to the carboxyterminal IQ domain of the human cardiac Na channel (hH1) in a Ca-dependent manner. Direct interaction of $\mathrm{CaM}$ with the IQ motif of $\mathrm{Na}_{\mathrm{v}} 1.5$ has been shown in other studies, however, the effects on the Na channels have been discordant: Kim et al. (31) showed that CaM modulates 
the C-terminal interaction with the III-IV linker (suggested to be necessary to stabilize the inactivation gate), to minimize sustained channel activity during depolarization, and to prevent cardiac arrhythmias that lead to sudden death; Young and Cadwell (33) showed a hyperpolarizing shift in the voltage dependence of activation, whereas no effect was reported by Deschênes et al. (34).

Recent reports have shown that also Na channels may be a target of CaMKII $(35,36)$. Wagner et al. (35) have shown that CaMKII coimmunoprecipitates with and phosphorylates $\mathrm{Na}$ channels. CaMKIII $\delta_{\mathrm{C}}$ overexpression in rabbit myocytes (acutely) and in transgenic mice (chronically) slows fast $\mathrm{I}_{\mathrm{Na}}$ inactivation, enhances late $\mathrm{I}_{\mathrm{Na}}$ (Fig. 2D), but also enhances accumulation of intermediate $\mathrm{I}_{\mathrm{Na}}$ inactivation (Fig. $2 B$ ), slows recovery from inactivation (Fig. $2 C$ ), and shifts steady-state inactivation of Na channels to more negative voltages (Fig. $2 A$ ) in a Ca-dependent manner (35). Moreover, all of these effects could be reversed with CaMKII inhibition (except impaired inactivation in TG mice). Deschênes et al. (34) found that inhibition of a CaM kinase (possibly CaMKIV) modifies cardiac Na channel inactivation, shifting the steady-state inactivation curve in the depolarizing direction, slowing entry into inactivated states, and hastening recovery from inactivation (KN-93 vs. KN-92 effects). They excluded CaMKII because the specific CaMKII inhibitor AIP did not seem to alter the Na channel gating. CaMKIV seems unlikely because it is poorly expressed in the heart and localizes to the nucleus. Maltsev et al. (36) tested the inhibition of CaMKII and CaM in failing vs. normal canine myocytes. They found that three of the above molecular mechanisms can be potentially involved in the effects of complex $\mathrm{Ca} / \mathrm{CaM} / \mathrm{CaMKII}$ modulation of the late $\mathrm{Na}$ current $\left(I_{\mathrm{NaL}}\right)$ characteristics: CaMKII slows the decay of $\mathrm{I}_{\mathrm{NaL}}$, Ca shifted steady-state inactivation towards more positive potentials (opposite the effect of CaMKII assessed by Wagner (35)). Thus, CaM and CaMKII effects on Na current may coexist.

The CaMKII-induced changes in $\mathrm{I}_{\mathrm{Na}}$ gating reported by Wagner (35) strikingly resemble those in a human genetic mutation in Nav1.5 (1795InsD) that is linked with simultaneous arrhythmogenic LQT3 and Brugada syndrome (37). In addition, CaMKII expression is upregulated and more active in $\mathrm{HF}(1,38,39)$ and arrhythmias are a major cause of death in HF. There are also reports of enhanced late $\mathrm{I}_{\mathrm{Na}}$ in $\mathrm{HF}$ (40). Thus, increased CaMKII-dependent $\mathrm{I}_{\mathrm{Na}}$ modulation in HF may be an acquired arrhythmogenic Na channel defect that could affect millions of people with HF.

\section{K Channels}

The transient outward $\mathrm{K}$ current $\left(\mathrm{I}_{\mathrm{to}}\right)$ is known to be critical for initiating cardiac repolarization in the early phase of action potentials. Despite its transient nature $\mathrm{I}_{\mathrm{to}}$ influences the overall duration of action potential as it profoundly influences phase 1 and the level of plateau, thereby affecting the currents that are active later in the action potential.

Tessier and colleagues (41) provided evidence that CaMKII regulates (slows) inactivation of $\mathrm{I}_{\text {to }}$ in human atrial myocytes thus contributing to atrial fibrillation. They showed that CaMKII inhibition accelerated $\mathrm{I}_{\text {to,fast }}$ inactivation, whereas okadaic acid (phosphatase inhibitor) had opposite effects (41). Similar results were obtained from rat ventricular myocytes (42) and in heterologeous expression of $\mathrm{K}_{\mathrm{V}} 4.2 / \mathrm{K}_{\mathrm{V}} 4.3(42,43)$. It was suggested that CaMKII acts on $\mathrm{K}_{\mathrm{V}} 4.3$ by a direct effect at Ser550, thereby prolonging open-state inactivation and accelerating the rate of recovery from inactivation (43). Recent evidence suggests that chronic inhibition of CaMKII in murine hearts results in APD shortening and prevents remodeling after myocardial infarction and excessive $\beta$-adrenergic stimulation (44). That study showed an enhancement of $\mathrm{I}_{\text {to }}$ during chronic CaMKII inhibition, suggesting that CaMKII may be involved in the regulation of repolarization in HF. However, acute dialysis of a CaMKIIinhibitory peptide into myocytes did not increase $\mathrm{I}_{\text {to }}(44)$, suggesting that $\mathrm{I}_{\text {to }}$ modulation is not 
caused by the acute effect of CaMKII dependent phosphorylation. Another recent report from Xiao et al. (45) has shown that $\mathrm{I}_{\text {to }}$ is downregulated in canine ventricular myocytes paced at 3 $\mathrm{Hz}$, and suggested that CaMKII is involved in the $\mathrm{I}_{\mathrm{to}}$ remodeling during sustained tachycardia via crosstalk with calcineurin/NFAT signaling.

Wagner et al. (46) studied how CaMKII alters $\mathrm{I}_{\text {to }}$, both acutely by adenoviral CaMKII overexpression in rabbit myocytes and chronically in CaMKII overexpressing transgenic mice with heart failure. CaMKII activation accelerates $\mathrm{I}_{\text {to }}$ recovery from inactivation for both $\mathrm{I}_{\text {to,fast }}$ and $\mathrm{I}_{\mathrm{to}, \text { slow }}$, and this appears to be an acute regulatory effect of phosphorylation by CaMKII, as it is acutely reversed by CaMKII inhibitors. There are also longer term alterations in $\mathrm{I}_{\text {to,fast }}$ and $\mathrm{I}_{\text {to,slow }}$ which may result from CaMKII-dependent changes in the expression and function of the $\mathrm{K}_{\mathrm{V}} 1.4$ underlying $\mathrm{I}_{\mathrm{to} \text {,slow, }}$, which was enhanced by both acute and transgenic CaMKII $\delta$ C-overexpression in rabbit and mouse myocytes. Conversely, $\mathrm{K}_{\mathrm{V}} 4.2 / 4.3$ (the molecular correlates of cardiac $\mathrm{I}_{\text {to,fast }}$ ) was decreased during chronic CaMKII $\delta \mathrm{C}$ overexpression in mice.

An interesting finding by Wang and colleagues (47) suggests that the $\mathrm{I}_{\mathrm{to}}$ inhibitor 4-AP binds to the $\mathrm{I}_{\text {to }}$ channel and facilitates $\mathrm{I}_{\mathrm{CaL}}$ via activation of CaMKII. Further studies are needed to test their hypothesis that a significant amount of inactive CaMKII forms molecular complex with $\mathrm{K}_{\mathrm{V}} 4.3$, and dissociation from $\mathrm{K}_{\mathrm{V}} 4.3$ facilitates CaMKII activation (48).

Differences in the expression pattern of $\mathrm{I}_{\mathrm{to}, \text { fast }}$ and $\mathrm{I}_{\mathrm{to} \text {,slow }}$ in different regions of the heart contribute to regional variations in AP duration. In addition, downregulation of $\mathrm{I}_{\mathrm{to}}$ is a central and consistent electrophysiological change in cardiac diseases (e.g., HF). Thus, it is very important to understand how CaMKII modulation of $\mathrm{I}_{\text {to }}$ influences the electrical heterogeneity of the myocardium in diseased and undiseased states.

$\mathrm{I}_{\mathrm{K} 1}$ not only stabilizes the myocyte resting potential, but also plays an important role in modulating cellular excitability and regulating membrane repolarization, and it is therefore an important determinant of action potential initiation and termination in cardiac cells. In mice with chronic CaMKII inhibition, where the AP is shortened and $\mathrm{I}_{\text {to }}$ enhanced, $\mathrm{I}_{\mathrm{K} 1}$ density was significantly upregulated (44); however, exposure of ventricular myocytes to acute CaMKII inhibition failed to increase $\mathrm{I}_{\mathrm{K} 1}$, suggesting that $\mathrm{I}_{\mathrm{K} 1}$ upregulation in these mice is an adaptive response to chronic CaMKII inhibition (increased functional expression of $\mathrm{I}_{\mathrm{K} 1}$ ), rather than the acute effect of reduced CaMKII dependent phosphorylation.

Wagner et al. (46) have shown that either short term (24 hr) or chronic transgenic CaMKII $\delta_{\mathrm{C}}$ overexpression reduces Kir2.1 gene expression and reduces $\mathrm{I}_{\mathrm{K} 1}$ (when acute modulation during measurement is prevented by CaMKII inhibition with AIP). Thus CaMKII $\delta_{\mathrm{C}}$ alters expression level of the channel responsible for $\mathrm{I}_{\mathrm{K} 1}$. This is consistent with several HF studies $(49,50)$ where $\mathrm{I}_{\mathrm{K} 1}$ is downregulated $\sim 40-50 \%$ and it raises the novel possibility that CaMKII (which is upregulated and more active in HF) might cause the depression of $\mathrm{I}_{\mathrm{K} 1}$ in $\mathrm{HF}$. Additionally, CaMKII may acutely modulate $\mathrm{I}_{\mathrm{K} 1}$ amplitude because acute CaMKII inhibition with AIP in the patch pipette reduced $\mathrm{I}_{\mathrm{K} 1}$. This was true in both control and CaMKII overxpressing myocytes suggesting some basal level of CaMKII-dependent $\mathrm{I}_{\mathrm{K} 1}$ activation.

$\mathrm{I}_{\mathrm{Ks}}$ is enhanced by intracellular Ca. This may be a consequence of allosteric interaction of CaM rather than phosphorylation by CaMKII, because a CaM inhibitor (W7), but not a CaMKII inhibitor (KN62) inhibited the Ca-induced $\mathrm{I}_{\mathrm{Ks}}$ enhancement (51). Interestingly, the $\alpha$ subunit of the $\mathrm{I}_{\mathrm{Ks}}$ channel, KCNQ1, has two potential binding sites for Ca-free CaM (apo-CaM), an IQ motif and a $\Phi$ motif, in its intracellular C-terminal region (52). Yeast two-hybrid assay also suggests that KCNQ1 associates with apo-CaM. Functional and biochemical analysis of LQTS mutations in the KCNQ1 C-terminus showed that disruption of CaM interaction with KCNQ1 
interfered with subunit assembly and that the resultant channels generated very small currents. $\mathrm{CaM}$ also affects $\mathrm{I}_{\mathrm{Ks}}$ channel gating, since channels with defective $\mathrm{Ca} / \mathrm{CaM}$ interaction show prominent inactivation not typical of this current (53). Thus, $\mathrm{I}_{\mathrm{Ks}}$ is enhanced by increases in $[\mathrm{Ca}]_{\mathrm{i}}$ at a physiological range via a calmodulin-dependent pathway, which does not involve phosphorylation.

Ca has been shown to play a role in the regulation of $\mathrm{I}_{\mathrm{f}}$ in guinea pig (54) and rabbit (55) sinoatrial node cells. Alterations in intracellular calcium during the cardiac cycle are involved in fine tuning the voltage-dependent properties of $\mathrm{I}_{\mathrm{f}}$ and may thus determine its relative contribution to pacemaking. It seems likely that CaM may be involved in this process, since three structurally unrelated $\mathrm{CaM}$ antagonists decreased $\mathrm{I}_{\mathrm{f}}$ and shifted its voltage-dependence of activation to more negative potentials. However, $\mathrm{I}_{\mathrm{f}}$ was not affected by inhibition of CaMKII. CaMKII has been found to regulate the pacemaker activity of the sinus node mainly via modulating $\mathrm{I}_{\mathrm{CaL}}$ inactivation and reactivation (56), and the local subsarcolemmal SR Ca releases which drive sinoatrial node cell automaticity, seem to involve basal phosphorylation of Ca cycling proteins by both PKA and CaMKII (57).

\section{RyRs}

RyR channels directly control SR Ca release in cardiac muscles, activating contraction during EC coupling. CaMKII associates with RyRs, but the molecular targeting is not yet completely resolved. CaMKII has been shown to phosphorylate RyR at Ser2809 (58) (non exclusive site, (59)) and Ser2815 (59). However, additional phosphorylation sites might also exist (60).

The functional consequences of RyR phosphorylation by CaMKII remain somewhat controversial. In early studies in planar bilayer reconstitution experiments CaMKII has been shown to either increase $(58,59,61)$ or decrease $(62)$ RyR open probabilities. In the natural ventricular myocyte environment, Li et al. (63) showed that, for a given SR Ca load and $\mathrm{I}_{\mathrm{CaL}}$ trigger, inhibition of endogenous CaMKII (with KN-93) decreased Ca release. These results were confirmed by Currie et al. (39) showing that the CaMKII peptide inhibitor AIP depresses Ca spark frequency in rabbit myocytes due to decreased endogenous CaMKII binding to RyR. Guo et al. (64) used saponin-permeabilized myocytes and found that both endogenous and exogenous CaMKII dramatically enhanced spontaneous SR Ca release events (Ca sparks) in a controlled setting where $\mathrm{I}_{\mathrm{Ca}}$, phospholamban effects and $\mathrm{SR}$ Ca load effects were prevented. A contrasting study (65) showed that adenoviral expression of a constitutively active CaMKII depresses SR Ca release, whereas a dominant negative CaMKII enhances it. Another group found that acute adenoviral overexpression of wild type CaMKII $\delta_{\mathrm{C}}$ only enhanced Ca sparks (21), as in the permeabilized myocyte studies noted above. Transgenic overexpression of CaMKII (3-fold increase in CaMKII activity) increased the fractional SR $\mathrm{Ca}$ release during ECC, diastolic and spontaneous SR Ca release. Indeed, the frequency of $\mathrm{Ca}$ sparks was greatly enhanced, demonstrating increased diastolic SR Ca leak, which could be reversed by CaMKII inhibition (20).

In a rabbit heart failure model of left ventricular pressure and volume overload, Ai et al. (1) showed that CaMKII expression is increased and more CaMKII is autophosphorylated and associated with the RyR2. In addition the HF myocyte had enhanced SR Ca leak, which was inhibited by CaMKII inhibition (thereby enhancing SR Ca content). This suggests a CaMKIIdependent phosphorylation of RyR in HF that is involved in the enhancement of diastolic SR Ca leak and decreased SR Ca load. Thus, CaMKII effects on RyR seem to be implicated in the phenotype of HF, both in the diastolic dysfunction (depletion of SR Ca stores), and in arrhythmogenesis (because the diastolic Ca release may activate NCX mediated $\mathrm{I}_{\mathrm{ti}}$ causing DADs and triggered arrhythmias). On the other hand, the CaMKII effect on RyR may not contribute appreciably to the depressed systolic function in HF. That is because the decreased 
SR Ca load is offset by a greater fractional release also attributable to CaMKII-dependent RyR modulation (63). The enhanced diastolic leak and fractional release during ECC may be manifestations of the same RyR2 activating effect of CaMKII.

CaMKII regulation of RyR seems important and most work points to an activating effect of CaMKII on RyR2. However, the fact that some observations differ, may indicate that there are multiple CaMKII effects on RyR2, possibly mediated by different target sites on RyR2 or auxiliary proteins. More work is needed to clarify this issue.

\section{Ins $\mathrm{P}_{3}$ Receptors}

Inositol 1,4,5-trisphosphate receptors $\left(\mathrm{InsP}_{3} \mathrm{Rs}\right)$ are intracellular Ca release channels that are present in cardiac myocytes, at much lower levels than RyRs. The type $2 \operatorname{InsP}_{3} \mathrm{R}\left(\mathrm{InsP}_{3} \mathrm{R} 2\right)$ is the predominant subtype in cardiac myocytes (66), but its role in heart is poorly understood. In atrial myocytes, InsP ${ }_{3} \mathrm{Rs}$ have been shown to exert positive inotropic and arrhythmogenic effects on EC coupling (67). Ventricular myocytes express $\operatorname{Ins}_{3} \mathrm{R}$, but at lower levels than atrial myocytes (68), and $\mathrm{InsP}_{3} \mathrm{Rs}$ are mainly in the nuclear envelope where they colocalize with CaMKII (69). CaMKII phosphorylates the $\mathrm{InsP}_{3} \mathrm{R} 2$, which may feedback on channel gating. In fact, incorporation of CaMKII-treated $\mathrm{InsP}_{3} \mathrm{R} 2$ into planar lipid bilayers revealed that $\mathrm{InsP}_{3}$-mediated channel open probability is significantly reduced by phosphorylation via CaMKII (69). The phosphorylation of InsP $\mathrm{P}_{3} \mathrm{R}$ by CaMKII may represent a mechanism through which activated CaMKII feeds back to terminate $\mathrm{InsP}_{3} \mathrm{R} 2$-dependent $\mathrm{Ca}$ release before exhaustion of the $\mathrm{Ca}$ store. Indeed, reports have shown that CaMKII activity is inhibitory with $\mathrm{InsP}_{3}$-mediated $\mathrm{Ca}$ release in Xenopus oocytes and HeLa cells $(70,71)$.

Wu et al. (72) recently demonstrated an Ins $\mathrm{P}_{3} \mathrm{R}$-CaMKII signaling in the nuclear envelope of adult ventricular myocytes which can participate in transcriptional regulation. The physiological hypertrophic agonist endothelin-1, which activates plasmalemmal G proteincoupled receptors and $\mathrm{InsP}_{3}$ production, elicits local nuclear envelope Ca release via $\mathrm{InsP}_{3} \mathrm{R}$. This local Ca release activates nuclear CaMKII, which triggers phosphorylation of a class II histone deacetylase (HDAC5) and HDAC5 nuclear export (derepressing transcription) (72). Remarkably, this Ca-dependent pathway cannot be activated by the global $\mathrm{Ca}$ transients that cause contraction at each heartbeat, suggesting a Ca-dependent reactive signaling circuit that is controlled separately from ECC-based Ca cycling. This is analogous to the very local control involved in Ca-induced $\mathrm{Ca}$ release during ECC and to $\mathrm{Ca}$-dependent inactivation of Ca current. These results are relevant since CaMKII activation and its ability to regulate HDAC5 nuclear shuttling represent a critical Ca-dependent signaling circuit for controlling cardiac hypertrophy and heart failure. In fact, $\mathrm{InsP}_{3} \mathrm{R} 2$ expression is enhanced in $\mathrm{HF}(1,73)$.

Whether InsP $\mathrm{P}_{3} \mathrm{R}$ in $\mathrm{HF}$ contributes to arrhythmogenesis besides transcriptional control in $\mathrm{HF}$ is not yet known. Recent work from Domeier et al. (68) showed that activation of $\mathrm{IP}_{3} \mathrm{R}$ facilitates SR Ca release through RyR release clusters and enhances the Ca transient during ECC, thus the $\mathrm{IP}_{3}$ signaling pathway may modulate ventricular ECC under conditions in which $\mathrm{IP}_{3} / \mathrm{IP}{ }_{3} \mathrm{R}$ signaling is altered, such as $\mathrm{HF}$.

\section{Modeling of CaMKII signaling}

CaMKII has numerous effects on transmembrane electrical processes and intracellular $\mathrm{Ca}$ fluxes, which can be both acute regulatory effects (phosphorylation), but can also alter the expression levels of ion channels (to alter protein transcription, translation, or trafficking). Transgenic mice overexpressing CaMKII exhibit arrhythmias $(22,35)$, which could have multiple causes via diverse mechanisms. Pharmacologic CaMKII inhibition has also been shown to be protective against arrhythmias (22). We have investigated in silico the effects of CaMKII overexpression on cardiac myocyte ionic currents and APs in a comprehensive 
computer model of ECC (4). By incorporating the modulatory effects on $\mathrm{I}_{\mathrm{Na}}, \mathrm{I}_{\mathrm{CaL}}$ and $\mathrm{I}_{\mathrm{to}}$ we showed that APs from rabbit myocytes overexpressing CaMKII are shorter compared to control (Figure $3 A$ left) as has been shown experimentally (46). However, when $\mathrm{I}_{\text {to }}$ expression is low (e.g., in $\mathrm{HF}$, or endocardial myocytes), the effects of $\mathrm{I}_{\mathrm{Na}}$ and $\mathrm{I}_{\mathrm{CaL}}$ would be predominant, thus potentially leading to a LQT3-like phenotype (Figure $3 \mathrm{~A}$ middle and right) and possibly EADinduced triggered arrhythmias. In fact, the prolongation of AP plateau may allow for the recovery and reactivation of $\mathrm{I}_{\mathrm{CaL}}$ that depolarizes the membrane and generates EADs (74). In addition, experimental and modeling data indicate that phoshorylation events promoting mode 2 gating of $\mathrm{I}_{\mathrm{CaL}}$ contribute to EADs and ventricular arrhythmias (22,75). We have also shown that CaMKII-induced Na channel loss of function effect may reduce AP rate of rise and conduction velocity, especially at fast heart rates $(\mathrm{BrS})(4)$. Heterogeneity of transmural ventricular repolarization has been linked to a variety of arrhythmic manifestations. A certain degree of transmural dispersion of repolarization is normal (Fig $3 B$ left), and may be attributed in part to differential expression of $\mathrm{I}_{\mathrm{to}}$ (where there is higher $\mathrm{I}_{\mathrm{to}}$ in myocytes at the epicardial side). If CaMKII prolongs APDs in the endocardium (Figure $3 A$ middle and right) and shortens APDs in the epicardium (Figure $3 A$ left), this could amplify transmural dispersion of repolarization (Fig. 3B, right), thus predisposing to the development of reentrant arrhythmias.

When incorporating in the ECC model the full spectrum of HF-induced changes, such as CaMKII mediated RyR-Ca sensitization, enhanced SR Ca leak, decreased $\mathrm{I}_{\mathrm{K} 1}$ and $\mathrm{I}_{\mathrm{to}}$ (besides the changes in $\mathrm{I}_{\mathrm{Na}}, \mathrm{I}_{\mathrm{CaL}}$ and $\mathrm{I}_{\text {to }}$ gating), coupled with other cellular changes, such as increased $\mathrm{I}_{\mathrm{NCX}}$, we observed DAD-induced triggered arrhythmias upon $\beta$-AR stimulation. DADs are a consequence of increased $[\mathrm{Ca}]_{\mathrm{SR}}$ activating SR Ca release and inward $\mathrm{I}_{\mathrm{NCX}}$, which depolarizes the membrane toward threshold for a triggered AP. HF myocytes were stimulated to steady state $(1 \mathrm{~Hz})$, then stimulation was stopped and DADs and spontaneous APs were monitored. DADs were not seen at baseline in control (not shown) or HF (Fig. 4, left). However, when simulating isoproterenol administration in HF myocytes only (i.e., doubling $\mathrm{I}_{\mathrm{CaL}}, \mathrm{I}_{\mathrm{Ks}}, \mathrm{SR} \mathrm{Ca}$ pump Ca affinity, RyR Ca affinity) DADs and triggered APs were seen upon cessation of 1Hz stimulation (Fig. 4, right).

Thus, the computer model shows that there are multiple targets and potential pathways through which CaMKII may be arrhythmogenic. Given the emerging role for CaMKII in cardiac pathogenesis it is important that computer models evolve to capture the dynamic range of CaMKII activity and the functional consequences on cardiomyocyte electrical activity (5-8).

\section{Conclusions}

It is increasingly clear that CaMKII has numerous ion channel and Ca regulatory targets in cardiac myocytes, and alters their function. Several of these channels are critically involved in altered electrophysiological and $\mathrm{Ca}$ handling properties in pathophysiological settings (e.g. $\mathrm{HF}$ ), where CaMKII may also have enhanced expression and function. Further studies are needed to clarify details of how CaMKII modulates these and other targets, and especially in the dynamic interactive environment of the cardiac myocyte. Because of the complexity of these interacting systems, computer modeling can be helpful in discerning the relative roles of different pathways and also in terms of testing how well we understand the individual and collective systems. The involvement of CaMKII in the electrical remodeling responsible for pro-arrhythmic signaling and contractile disfunction (e.g. in HF) suggests that this kinase may be a promising therapeutic target in the treatment of common forms of cardiac disease.

\section{Acknowledgments}

Sources of support: NIH grants (R37-HL30077, R01-HL64274, P01-HL80101) and from the Fondation Leducq. 


\section{References}

1. Ai X, Curran JW, Shannon TR, Bers DM, Pogwizd SM. $\mathrm{Ca}^{2+} /$ Calmodulin-Dependent Protein Kinase Modulates Cardiac Ryanodine Receptor Phosphorylation and Sarcoplasmic Reticulum $\mathrm{Ca}^{2+}$ Leak in Heart Failure. Circ Res 2005;97(12):1314-1322. [PubMed: 16269653]

2. Zhang T, Maier LS, Dalton ND, Miyamoto S, Ross J Jr. Bers DM, Brown JH. The \{delta $\}$ C Isoform of CaMKII Is Activated in Cardiac Hypertrophy and Induces Dilated Cardiomyopathy and Heart Failure. Circ Res 2003;92(8):912-919. [PubMed: 12676814]

3. Wang Y, Tandan S, Cheng J, Yang C, Nguyen L, Sugianto J, Johnstone JL, Sun Y, Hill JA. Ca ${ }^{2+}$ / Calmodulin-dependent Protein Kinase II-dependent Remodeling of $\mathrm{Ca}^{2+}$ Current in Pressure Overload Heart Failure. J. Biol. Chem 2008;283(37):25524-25532. [PubMed: 18622016]

4. Grandi E, Puglisi JL, Wagner S, Maier LS, Severi S, Bers DM. Simulation of Ca-CalmodulinDependent Protein Kinase II on Rabbit Ventricular Myocyte Ion Currents and Action Potentials. Biophys. J 2007;93(11):3835-3847. [PubMed: 17704163]

5. Hund TJ, Rudy Y. Rate Dependence and Regulation of Action Potential and Calcium Transient in a Canine Cardiac Ventricular Cell Model. Circulation 2004;110(20):3168-3174. [PubMed: 15505083]

6. Livshitz LM, Rudy Y. Regulation of $\mathrm{Ca}^{2+}$ and electrical alternans in cardiac myocytes: Role of CaMKII and repolarizing currents. Am J Physiol Heart Circ Physiol. 200701347.02006

7. Hund TJ, Decker KF, Kanter E, Mohler PJ, Boyden PA, Schuessler RB, Yamada KA, Rudy Y. Role of activated CaMKII in abnormal calcium homeostasis and INa remodeling after myocardial infarction: Insights from mathematical modeling. 2008;45(3):420.

8. Saucerman JJ, Bers DM. Calmodulin Mediates Differential Sensitivity of CaMKII and Calcineurin to Local $\mathrm{Ca}^{2+}$ in Cardiac Myocytes. Biophys. J 2008;95(10):4597-4612. [PubMed: 18689454]

9. Pitt GS, Zuhlke RD, Hudmon A, Schulman H, Reuter H, Tsien RW. Molecular Basis of Calmodulin Tethering and $\mathrm{Ca}^{2+}$-dependent Inactivation of L-type $\mathrm{Ca}^{2+}$ Channels. J. Biol. Chem 2001;276(33): 30794-30802. [PubMed: 11408490]

10. Bers DM. Cardiac excitation-contraction coupling. Nature 2002;415(6868):198-205. [PubMed: 11805843]

11. Hryshko LV, Bers DM. Ca current facilitation during postrest recovery depends on Ca entry. Am J Physiol Heart Circ Physiol 1990;259(3):H951-H961.

12. Ross J Jr. Miura T, Kambayashi M, Eising GP, Ryu K-H. Adrenergic Control of the Force-Frequency Relation. Circulation 1995;92(8):2327-2332. [PubMed: 7554218]

13. Guo J, Duff HJ. Inactivation of ICa-L is the major determinant of use-dependent facilitation in rat cardiomyocytes. J Physiol 2003;547(3):797-805. [PubMed: 12562907]

14. Guo J, Duff HJ. Calmodulin kinase II accelerates L-type $\mathrm{Ca}^{2+}$ current recovery from inactivation and compensates for the direct inhibitory effect of $\left[\mathrm{Ca}^{2+}\right] \mathrm{i}$ in rat ventricular myocytes. J Physiol 2006;574 (2):509-518. [PubMed: 16627565]

15. Anderson ME, Braun AP, Schulman H, Premack BA. Multifunctional $\mathrm{Ca}^{2+} / \mathrm{cal}$ modulin-dependent protein kinase mediates $\mathrm{Ca}^{2+}$-induced enhancement of the L-type $\mathrm{Ca}^{2+}$ current in rabbit ventricular myocytes. Circ Res 1994;75(5):854-861. [PubMed: 7923631]

16. Yuan W, Bers DM. Ca-dependent facilitation of cardiac Ca current is due to Ca-calmodulin-dependent protein kinase. Am J Physiol Heart Circ Physiol 1994;267(3):H982-H993.

17. Xiao RP, Cheng H, Lederer WJ, Suzuki T, Lakatta EG. Dual regulation of $\mathrm{Ca}^{2+} /$ calmodulindependent kinase II activity by membrane voltage and by calcium influx. Proc Natl Acad Sci U S A 1994;91(20):9659-9663. [PubMed: 7937825]

18. Dzhura I, Wu Y, Colbran RJ, Balser JR, Anderson ME. Calmodulin kinase determines calciumdependent facilitation of L-type calcium channels. Nat Cell Biol 2000;2(3):173-177. [PubMed: 10707089]

19. Grueter CE, Abiria SA, Dzhura I, Wu Y, Ham A-JL, Mohler PJ, Anderson ME, Colbran RJ. L-Type $\mathrm{Ca}^{2+}$ Channel Facilitation Mediated by Phosphorylation of the [beta] Subunit by CaMKII. 2006;23 (5):641.

20. Maier LS, Zhang T, Chen L, DeSantiago J, Brown JH, Bers DM. Transgenic CaMKII delta\}C Overexpression Uniquely Alters Cardiac Myocyte $\mathrm{Ca}^{2+}$ Handling: Reduced SR Ca ${ }^{2+}$ Load and Activated SR Ca ${ }^{2+}$ Release. Circ Res 2003;92(8):904-911. [PubMed: 12676813] 
21. Kohlhaas M, Zhang T, Seidler T, Zibrova D, Dybkova N, Steen A, Wagner S, Chen L, Heller Brown J, Bers DM, Maier LS. Increased Sarcoplasmic Reticulum Calcium Leak but Unaltered Contractility by Acute CaMKII Overexpression in Isolated Rabbit Cardiac Myocytes. Circ Res 2006;98(2):235244. [PubMed: 16373600]

22. Wu Y, Temple J, Zhang R, Dzhura I, Zhang W, Trimble R, Roden DM, Passier R, Olson EN, Colbran RJ, Anderson ME. Calmodulin Kinase II and Arrhythmias in a Mouse Model of Cardiac Hypertrophy. Circulation 2002;106(10):1288-1293. [PubMed: 12208807]

23. Cribbs LL, Martin BL, Schroder EA, Keller BB, Delisle BP, Satin J. Identification of the T-Type Calcium Channel (CaV3.1d) in Developing Mouse Heart. Circ Res 2001;88(4):403-407. [PubMed: 11230107]

24. Ferron L, Capuano V, Ruchon Y, Deroubaix E, Coulombe A, Renaud J-F. Angiotensin II Signaling Pathways Mediate Expression of Cardiac T-Type Calcium Channels. Circ Res 2003;93(12):12411248. [PubMed: 14615287]

25. Nuss HB, Houser SR. T-type $\mathrm{Ca}^{2+}$ current is expressed in hypertrophied adult feline left ventricular myocytes. Circ Res 1993;73(4):777-782. [PubMed: 8396509]

26. Izumi T, Kihara Y, Sarai N, Yoneda T, Iwanaga Y, Inagaki K, Onozawa Y, Takenaka H, Kita T, Noma A. Reinduction of T-Type Calcium Channels by Endothelin-1 in Failing Hearts In Vivo and in Adult Rat Ventricular Myocytes In Vitro. Circulation 2003;108(20):2530-2535. [PubMed: 14581409]

27. Barrett PQ, Lu H-K, Colbran R, Czernik A, Pancrazio JJ. Stimulation of unitary T-type $\mathrm{Ca}^{2+} \mathrm{channel}^{2}$ currents by calmodulin-dependent protein kinase II. Am J Physiol Cell Physiol 2000;279(6):C1694C1703. [PubMed: 11078683]

28. Welsby PJ, Wang H, Wolfe JT, Colbran RJ, Johnson ML, Barrett PQ. A Mechanism for the Direct Regulation of T-Type Calcium Channels by $\mathrm{Ca}^{2+} /$ Calmodulin-Dependent Kinase II. J. Neurosci 2003;23(31):10116-10121. [PubMed: 14602827]

29. Colomer JM, Mao L, Rockman HA, Means AR. Pressure Overload Selectively Up-Regulates $\mathrm{Ca}^{2+}$ / Calmodulin-Dependent Protein Kinase II in Vivo. Mol Endocrinol 2003;17(2):183-192. [PubMed: 12554746]

30. Wingo TL, Shah VN, Anderson ME, Lybrand TP, Chazin WJ, Balser JR. An EF-hand in the sodium channel couples intracellular calcium to cardiac excitability. 2004;11(3):219.

31. Kim J, Ghosh S, Liu H, Tateyama M, Kass RS, Pitt GS. Calmodulin Mediates $\mathrm{Ca}^{2+}$ Sensitivity of Sodium Channels. J. Biol. Chem 2004;279(43):45004-45012. [PubMed: 15316014]

32. Tan HL, Kupershmidt S, Zhang R, Stepanovic S, Roden DM, Wilde AAM, Anderson ME, Balser JR. A calcium sensor in the sodium channel modulates cardiac excitability. 2002;415(6870):442.

33. Young KA, Caldwell JH. Modulation of skeletal and cardiac voltage-gated sodium channels by calmodulin. J Physiol 2005;565(2):349-370. [PubMed: 15746172]

34. Deschenes I, Neyroud N, DiSilvestre D, Marban E, Yue DT, Tomaselli GF. Isoform-Specific Modulation of Voltage-Gated $\mathrm{Na}^{+}$Channels by Calmodulin. Circ Res 2002;90(4):e49-e57. [PubMed: 11884381]

35. Wagner S, Dybkova N, Rasenack ECL, Jacobshagen C, Fabritz L, Kirchhof P, Maier SKG, Zhang T, Hasenfuss G, Brown JH, Bers DM, Maier LS. $\mathrm{Ca}^{2+} /$ calmodulin-dependent protein kinase II regulates cardiac $\mathrm{Na}^{+}$channels. J. Clin. Invest 2006;116(12):3127-3138. [PubMed: 17124532]

36. Maltsev VA, Reznikov V, Undrovinas NA, Sabbah HN, Undrovinas A. Modulation of late sodium current by $\mathrm{Ca}^{2+}$, calmodulin, and CaMKII in normal and failing dog cardiomyocytes: similarities and differences. Am J Physiol Heart Circ Physiol 2008;294(4):H1597-H1608. [PubMed: 18203851]

37. Veldkamp MW, Viswanathan PC, Bezzina C, Baartscheer A, Wilde AAM, Balser JR. Two Distinct Congenital Arrhythmias Evoked by a Multidysfunctional Na ${ }^{+}$Channel. Circ Res 2000;86(9):91e97e.

38. Kirchhefer U, Schmitz W, Scholz H, Neumann J. Activity of cAMP-dependent protein kinase and $\mathrm{Ca}^{2+} /$ calmodulin-dependent protein kinase in failing and nonfailing human hearts. Cardiovascular Research 1999;42(1):254. [PubMed: 10435018]

39. Currie S, Loughrey CM, Craig MA, Smith GL. Calcium/calmodulin-dependent protein kinase IIdelta associates with the ryanodine receptor complex and regulates channel function in rabbit heart. Biochem J 2004;377(Pt 2):357-366. [PubMed: 14556649] 
40. Valdivia CR, Chu WW, Pu J, Foell JD, Haworth RA, Wolff MR, Kamp TJ, Makielski JC. Increased late sodium current in myocytes from a canine heart failure model and from failing human heart. Journal of Molecular and Cellular Cardiology 2005;38(3):475. [PubMed: 15733907]

41. Tessier S, Karczewski P, Krause E-G, Pansard Y, Acar C, Lang-Lazdunski M, Mercadier J-J, Hatem SN. Regulation of the Transient Outward $\mathrm{K}^{+}$Current by $\mathrm{Ca}^{2+} /$ Calmodulin-Dependent Protein Kinases II in Human Atrial Myocytes. Circ Res 1999;85(9):810-819. [PubMed: 10532949]

42. Colinas O, Gallego M, Setien R, Lopez-Lopez JR, Perez-Garcia MT, Casis O. Differential modulation of Kv4.2 and Kv4.3 channels by calmodulin-dependent protein kinase II in rat cardiac myocytes. Am J Physiol Heart Circ Physiol 2006;291(4):H1978-H1987. [PubMed: 16648177]

43. Sergeant GP, Ohya S, Reihill JA, Perrino BA, Amberg GC, Imaizumi Y, Horowitz B, Sanders KM, Koh SD. Regulation of Kv4.3 currents by $\mathrm{Ca}^{2+} /$ calmodulin-dependent protein kinase II. Am J Physiol Cell Physiol 2005;288(2):C304-C313. [PubMed: 15456698]

44. Li J, Marionneau C, Zhang R, Shah V, Hell JW, Nerbonne JM, Anderson ME. Calmodulin Kinase II Inhibition Shortens Action Potential Duration by Upregulation of $\mathrm{K}^{+}$Currents. Circ Res 2006;99 (10):1092-1099. [PubMed: 17038644]

45. Xiao L, Coutu P, Villeneuve LR, Tadevosyan A, Maguy A, Le Bouter S, Allen BG, Nattel S. Mechanisms Underlying Rate-Dependent Remodeling of Transient Outward Potassium Current in Canine Ventricular Myocytes. Circ Res 2008;103(7):733-742. [PubMed: 18723449]

46. Wagner S, Hacker E, Grandi E, Weber S, Dybkova N, Sossalla S, Sowa T, Bers D, Maier L. Ca/ Calmodulin Kinase II Differentially Modulates Potassium Currents. Circ Arrhythmia Electrophysiol. (under revision)

47. Wang Y, Cheng J, Tandan S, Jiang M, McCloskey DT, Hill JA. Transient-Outward $\mathrm{K}^{+}$Channel Inhibition Facilitates L-Type $\mathrm{Ca}^{2+}$ Current in Heart. Journal of Cardiovascular Electrophysiology 2006;17(3):298-304. [PubMed: 16643405]

48. Keskanokwong T, Cheng J, Wang Y. Abstract 1536: The CaMKII-Ito Channel Functional Unit in Cardiomyocytes. Circulation 2008;118(18_MeetingAbstracts):S_346-b-

49. Pogwizd SM, Schlotthauer K, Li L, Yuan W, Bers DM. Arrhythmogenesis and Contractile Dysfunction in Heart Failure: Roles of Sodium-Calcium Exchange, Inward Rectifier Potassium Current, and Residual \{beta\}-Adrenergic Responsiveness. Circ Res 2001;88(11):1159-1167. [PubMed: 11397782]

50. Beuckelmann D, Näbauer M, Erdmann E. Alterations of $\mathrm{K}^{+}$currents in isolated human ventricular myocytes from patients with terminal heart failure. Circ Res 1993;73:379-385. [PubMed: 8330380]

51. Nitta J, Furukawa T, Marumo F, Sawanobori T, Hiraoka M. Subcellular mechanism for $\mathrm{Ca}^{2+}$ dependent enhancement of delayed rectifier $\mathrm{K}^{+}$current in isolated membrane patches of guinea pig ventricular myocytes. Circ Res 1994;74(1):96-104. [PubMed: 8261599]

52. Yus-Najera E, Santana-Castro I, Villarroel A. The Identification and Characterization of a Noncontinuous Calmodulin-binding Site in Noninactivating Voltage-dependent KCNQ Potassium Channels. J. Biol. Chem 2002;277(32):28545-28553. [PubMed: 12032157]

53. Ghosh S, Nunziato DA, Pitt GS. KCNQ1 Assembly and Function Is Blocked by Long-QT Syndrome Mutations That Disrupt Interaction With Calmodulin. Circ Res 2006;98(8):1048-1054. [PubMed: 16556866]

54. Rigg L, Mattick PAD, Heath BM, Terrar DA. Modulation of the hyperpolarization-activated current (If) by calcium and calmodulin in the guinea-pig sino-atrial node. Cardiovasc Res 2003;57(2):497504. [PubMed: 12566122]

55. Hagiwara N, Irisawa $\mathrm{H}$. Modulation by intracellular $\mathrm{Ca}^{2+}$ of the hyperpolarization-activated inward current in rabbit single sino-atrial node cells. J Physiol 1989;409(1):121-141. [PubMed: 2479735]

56. Vinogradova TM, Zhou Y-Y, Bogdanov KY, Yang D, Kuschel M, Cheng H, Xiao R-P. Sinoatrial Node Pacemaker Activity Requires $\mathrm{Ca}^{2+} /$ Calmodulin-Dependent Protein Kinase II Activation. Circ Res 2000;87(9):760-767. [PubMed: 11055979]

57. Sirenko S, Li Y, Yang D, Lukyanenko Y, Lakatta EG, Vinogradova TM. Abstract 1537: Basal Phosphorylation Of $\mathrm{Ca}^{2+}$ Cycling Proteins By Both PKA And CAMKII is Required For Robust Generation Of Local Subsarcolemmal $\mathrm{Ca}^{2+}$ Releases To Drive Sinoatrial Node Cell Automaticity. Circulation. 2008 118;(18_MeetingAbstracts):S_346-c- 
58. Witcher DR, Kovacs RJ, Schulman H, Cefali DC, Jones LR. Unique phosphorylation site on the cardiac ryanodine receptor regulates calcium channel activity. J. Biol. Chem 1991;266(17):1114411152. [PubMed: 1645727]

59. Wehrens XHT, Lehnart SE, Reiken SR, Marks AR. Ca ${ }^{2+} /$ Calmodulin-Dependent Protein Kinase II Phosphorylation Regulates the Cardiac Ryanodine Receptor. Circ Res 2004;94(6):e61-e70. [PubMed: 15016728]

60. Rodriguez P, Bhogal MS, Colyer J. Stoichiometric Phosphorylation of Cardiac Ryanodine Receptor on Serine 2809 by Calmodulin-dependent Kinase II and Protein Kinase A. J. Biol. Chem 2003;278 (40):38593-38600. [PubMed: 14514795]

61. Hain J, Onoue H, Mayrleitner M, Fleischer S, Schindler H. Phosphorylation Modulates the Function of the Calcium Release Channel of Sarcoplasmic Reticulum from Cardiac Muscle. J. Biol. Chem 1995;270(5):2074-2081. [PubMed: 7836435]

62. Lokuta AJ, Rogers TB, Lederer WJ, Valdivia HH. Modulation of cardiac ryanodine receptors of swine and rabbit by a phosphorylation-dephosphorylation mechanism. J Physiol 1995;487(Pt3):609-622. [PubMed: 8544125]

63. Li L, Satoh H, Ginsburg KS, Bers DM. The effect of $\mathrm{Ca}^{2+}$-calmodulin-dependent protein kinase II on cardiac excitation-contraction coupling in ferret ventricular myocytes. J Physiol 1997;501(Pt1): 17-31. [PubMed: 9174990]

64. Guo T, Zhang T, Mestril R, Bers DM. Ca ${ }^{2+} /$ Calmodulin-Dependent Protein Kinase II Phosphorylation of Ryanodine Receptor Does Affect Calcium Sparks in Mouse Ventricular Myocytes. Circ Res 2006;99(4):398-406. [PubMed: 16840718]

65. Yang D, Zhu W-Z, Xiao B, Brochet DXP, Chen SRW, Lakatta EG, Xiao R-P, Cheng H. Ca ${ }^{2+/}$ Calmodulin Kinase II-Dependent Phosphorylation of Ryanodine Receptors Suppresses $\mathrm{Ca}^{2+}$ Sparks and $\mathrm{Ca}^{2+}$ Waves in Cardiac Myocytes. Circ Res 2007;100(3):399-407. [PubMed: 17234969]

66. Perez PJ, Ramos-Franco J, Fill M, Mignery GA. Identification and Functional Reconstitution of the Type 2 Inositol 1,4,5-Trisphosphate Receptor from Ventricular Cardiac Myocytes. J.Biol. Chem 1997;272(38):23961-23969. [PubMed: 9295347]

67. Zima AV, Blatter LA. Inositol-1,4,5-trisphosphate-dependent $\mathrm{Ca}^{2+}$ signalling in cat atrial excitationcontraction coupling and arrhythmias. J Physiol 2004;555(3):607-615. [PubMed: 14754996]

68. Domeier TL, Zima AV, Maxwell JT, Huke S, Mignery GA, Blatter LA. IP3 receptor-dependent $\mathrm{Ca}^{2+}$ release modulates excitation-contraction coupling in rabbit ventricular myocytes. Am J Physiol Heart Circ Physiol 2008;294(2):H596-H604. [PubMed: 18055509]

69. Bare DJ, Kettlun CS, Liang M, Bers DM, Mignery GA. Cardiac Type 2 Inositol 1,4,5-Trisphosphate Receptor: Interaction and modulation by calcium/calmodulin-dependent protein kinase II. J. Biol. Chem 2005;280(16):15912-15920. [PubMed: 15710625]

70. Matifat F, Hague F, Brûlé G, Collin T. Regulation of InsP3-mediated $\mathrm{Ca}^{2+}$ release by CaMKII in Xenopus oocytes. Pflügers Archiv European Journal of Physiology 2001;441(6):796-801.

71. Zhu DM, Tekle E, Chock PB, Huang CY. Reversible Phosphorylation as a Controlling Factor for Sustaining Calcium Oscillations in HeLa Cells: Involvement of Calmodulin-Dependent Kinase II and a Calyculin A-Inhibitable Phosphatase. Biochemistry 1996;35(22):7214-7223. [PubMed: 8679550]

72. Wu X, Zhang T, Bossuyt J, Li X, McKinsey T, Dedman J, Olson E, Chen J, Brown J, Bers D. Local InsP3-dependent perinuclear $\mathrm{Ca}^{2+}$ signaling in cardiac myocyte excitation-transcription coupling. $\mathrm{J}$ Clin Invest 2006;116(3):675-682. [PubMed: 16511602]

73. Go L, Moschella M, Watras J, Handa K, Fyfe B, Marks A. Differential regulation of two types of intracellular calcium release channels during end-stage heart failure. J Clin Invest 1995;95(2):888894. [PubMed: 7860772]

74. Clancy CE, Rudy Y. $\mathrm{Na}^{+}$Channel Mutation That Causes Both Brugada and Long-QT Syndrome Phenotypes: A Simulation Study of Mechanism. Circulation 2002;105(10):1208-1213. [PubMed: 11889015]

75. Tanskanen AJ, Greenstein JL, O'Rourke B, Winslow RL. The Role of Stochastic and Modal Gating of Cardiac L-Type $\mathrm{Ca}^{2+}$ Channels on Early After-Depolarizations. 2005;88(1):85. 


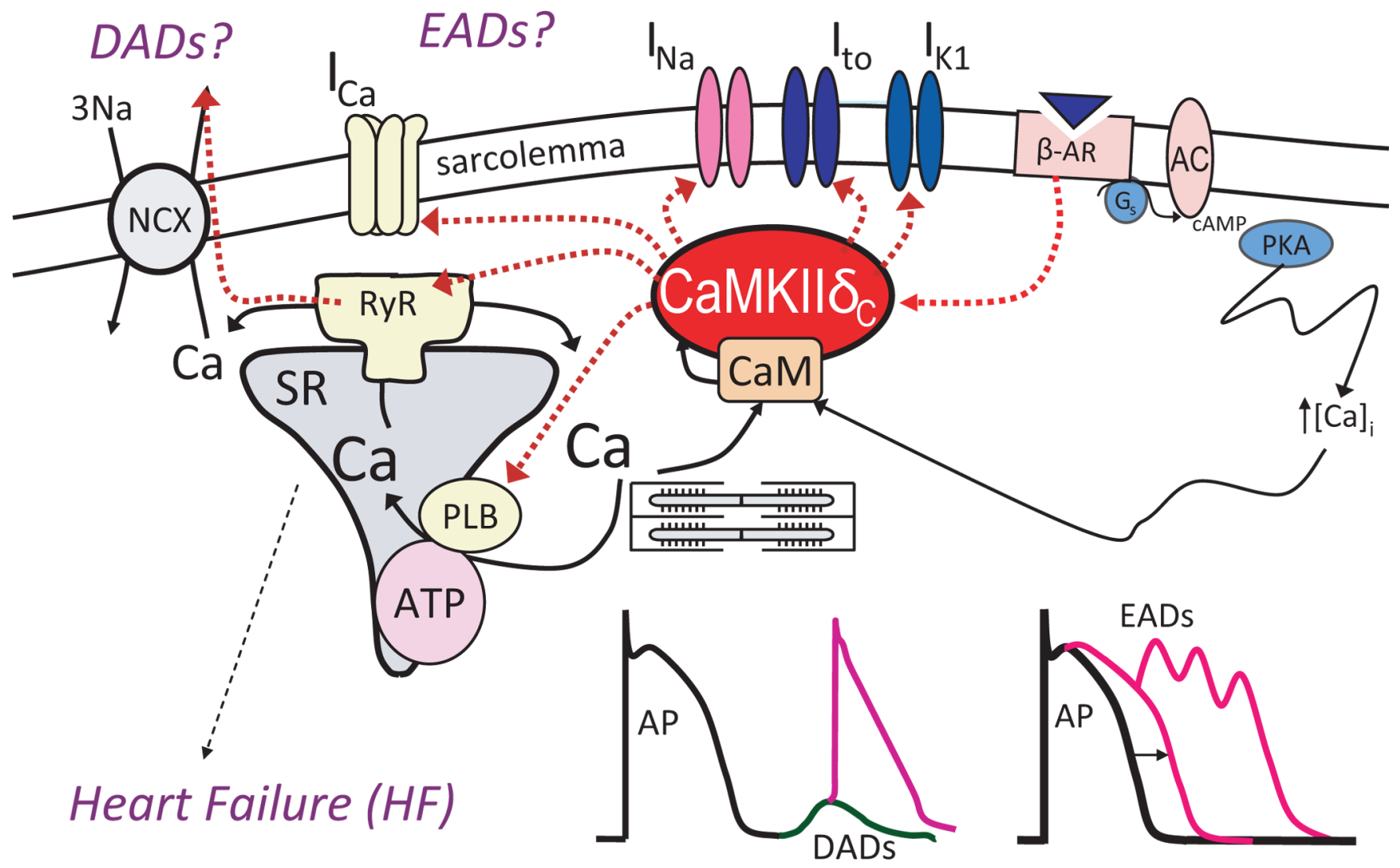

Figure 1.

CaMKII influences EC coupling by affecting several electrical and Ca handling proteins, including phospholamban (PLB), SR Ca release channels (RyR), and L-type Ca channels responsible for transarcolemmal $\mathrm{Ca}$ influx $\left(\mathrm{I}_{\mathrm{CaL}}\right.$ ). In addition, $\mathrm{Na}$ channels (responsible for $\mathrm{I}_{\mathrm{Na}}$ ) and $\mathrm{K}$ channels (e.g., $\mathrm{I}_{\mathrm{to}}$ and $\mathrm{I}_{\mathrm{K} 1}$ ) have shown to be regulated by CaMKII. By exerting multiple effects on these numerous targets CaMKII can simultaneously favor heart failure and arrhythmias. 


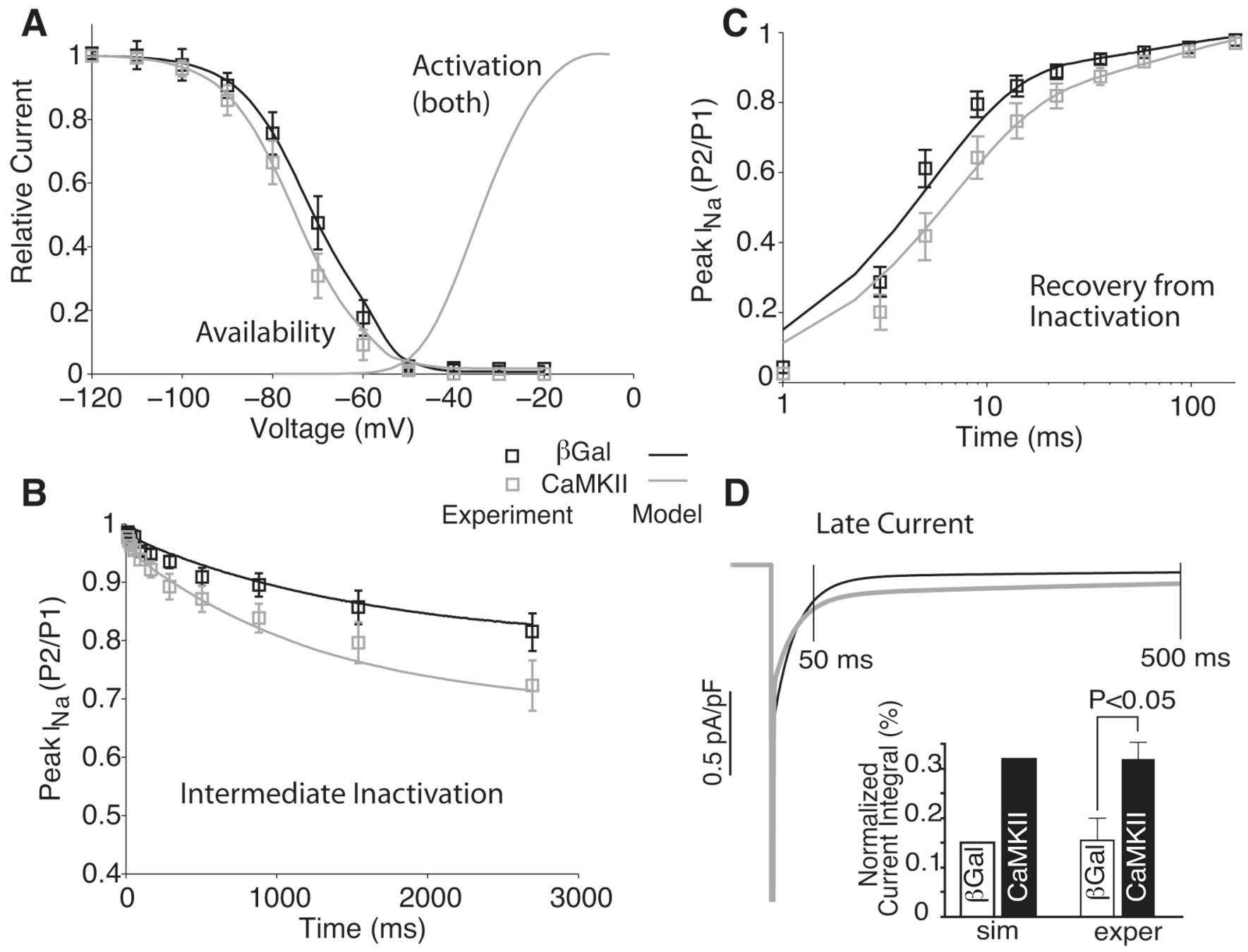

Figure 2.

Modulation of $\mathrm{Na}$ current gating upon adenoviral CaMKII $\delta_{\mathrm{C}}$ overexpression (vs. control $\beta$ galactosidase) in adult rabbit ventricular myocytes. Experimental data by Wagner et al. (35) and simulated results with our model (4) are reported. With CaMKII $\mathrm{I}_{\mathrm{Na}}$ availability is shifted towards more negative potentials, whereas activation is unchanged $(\mathrm{A})$, more $\mathrm{I}_{\mathrm{Na}}$ accumulates in intermediate inactivation $(\mathrm{B}), \mathrm{I}_{\mathrm{Na}}$ recovers more slowly from inactivation $(\mathrm{C})$ and there is more sustained current upon prolonged depolarization (D). Modified from ref. (4). 


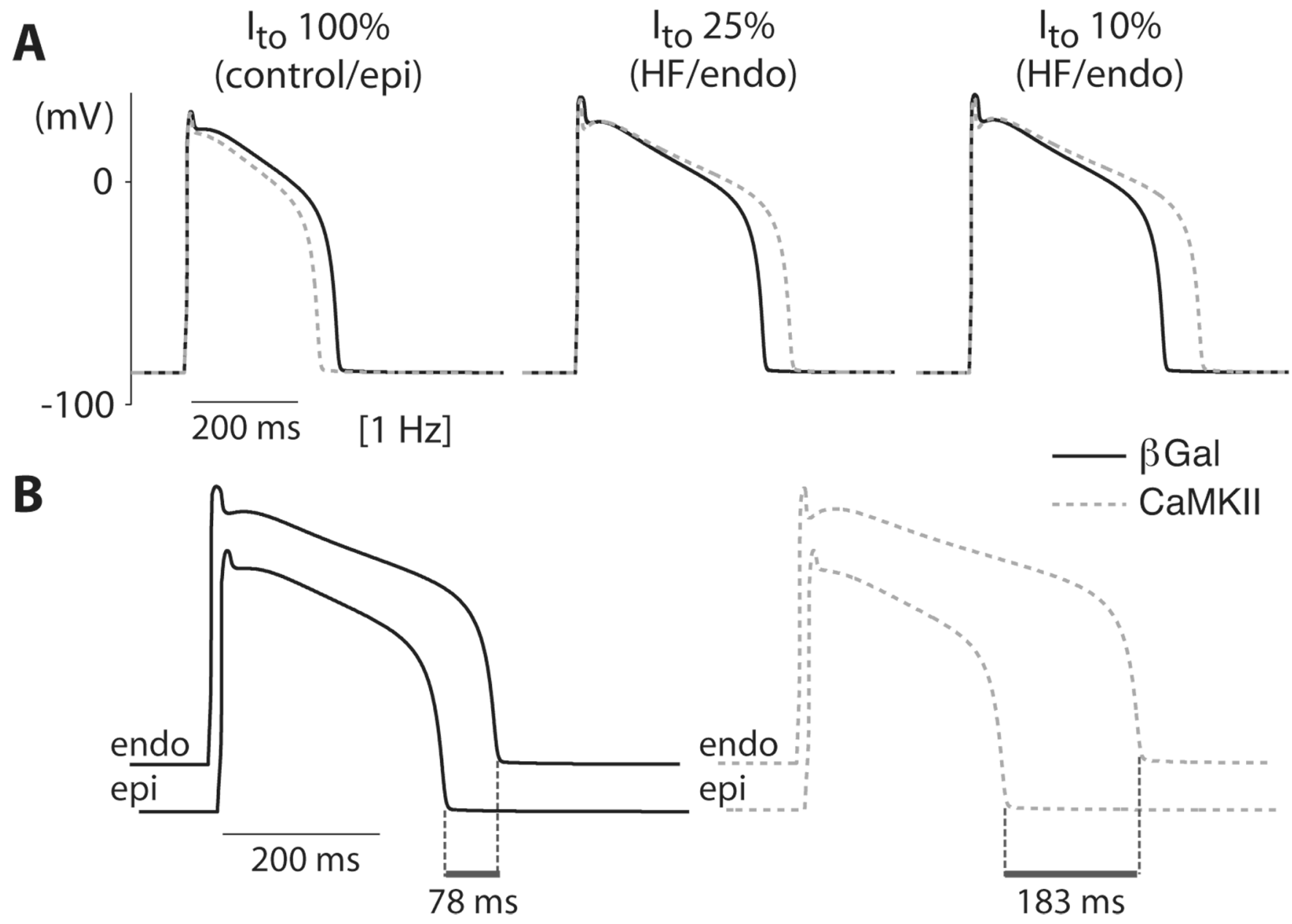

Figure 3.

Simulated APs at $1 \mathrm{~Hz}$ in $\beta \mathrm{Gal}$ and $\mathrm{CaMKII} \delta_{\mathrm{C}^{-}}$overexpressing cardiac myocytes in the presence of $100 \%(A$, left $) 25 \%$ (A, middle), and $10 \%(A$, right $) I_{\mathrm{to}}$. When $I_{\mathrm{to}}$ is fully expressed (A, epi or control), CaMKII shortens the AP, whereas the AP is prolonged due to $I_{\text {to }}$ downregulation (e.g., endo or $H F$ ). This could amplify transmural dispersion of repolarization ( $B$, endo-epi: $78 \mathrm{~ms}$ for $\beta \mathrm{Gal}$ vs. $183 \mathrm{~ms}$ for CaMKII), which may predispose cells to reentry phenomena. Modified from ref. (4). 


\section{HF (w/CaMKII hyperactivity)}
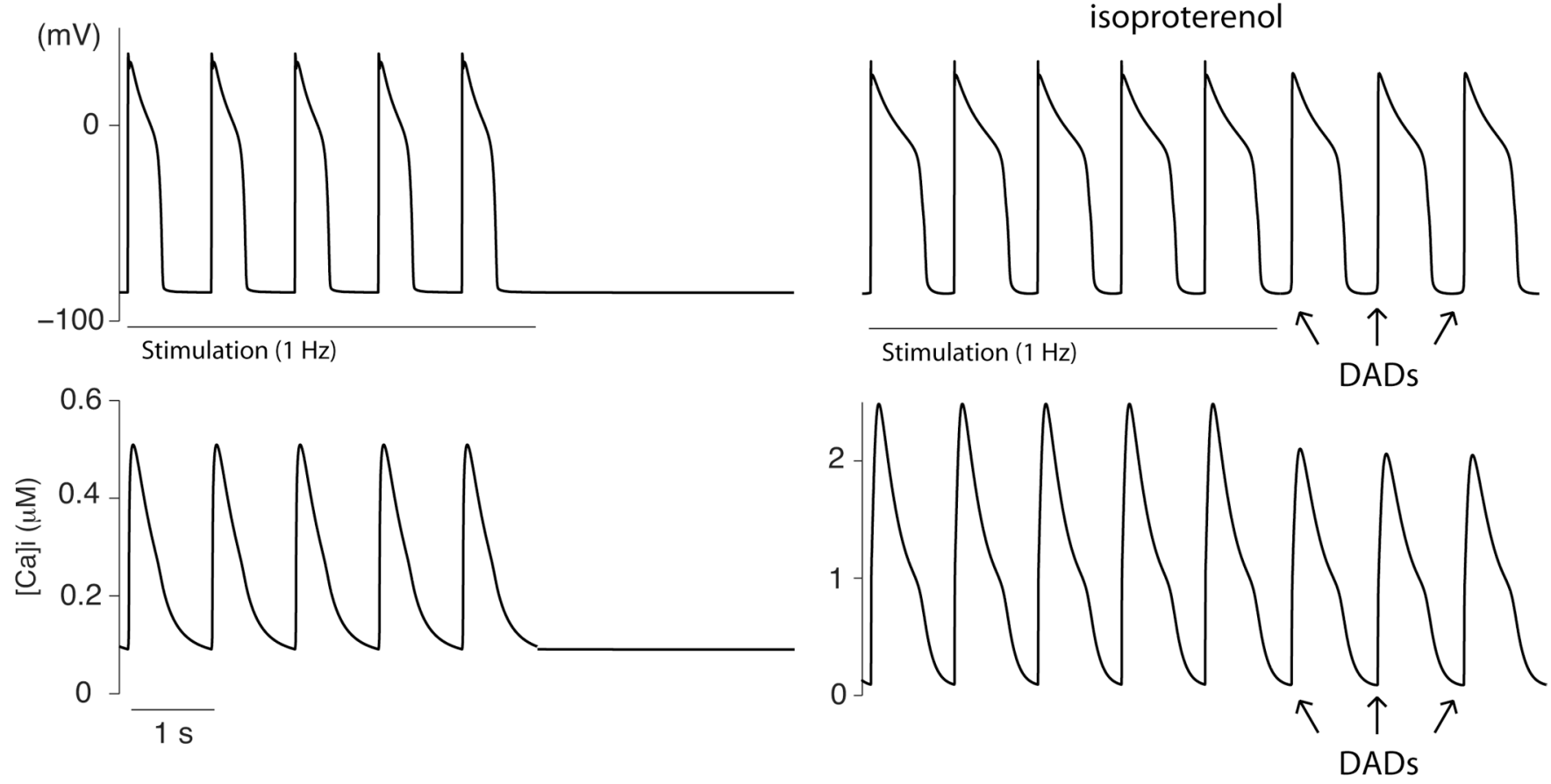

Figure 4.

(A) Stimulation of steady-state AP and Ca transients followed by a period of rest in digital $\mathrm{HF}$ cell (left) and with isoproterenol (right) at $1 \mathrm{~Hz}$. In isoproterenol cessation of $1-\mathrm{Hz}$ stimulation, leads to spontaneous SR Ca release (right, lower panel) activating inward $\mathrm{I}_{\mathrm{NCX}}$, which depolarizes the membrane generating DADs (right, upper panel). DADs were not seen in HF (left). 